\title{
Nanocellulose Characterization Challenges
}

\author{
Ana Balea, ${ }^{\mathrm{a}}$ Angeles Blanco, ${ }^{\mathrm{a}, *}$ Marc Delgado-Aguilar, ${ }^{\mathrm{b}}$ M. Concepcion Monte, ${ }^{\mathrm{a}}$ \\ Quim Tarrés, ${ }^{\mathrm{b}}$ Elena Fuente, ${ }^{\mathrm{a}}$ Per Mutjé, ${ }^{\mathrm{b}}$ and Carlos Negro ${ }^{\mathrm{a}}$
}

Despite the extraordinary properties of nanocellulose (NC), as confirmed through two decades of exhaustive research, addressing an array of potential applications, the NC market is still far from reaching its full potential. Among the main causes is the lack of process-adapted measuring tools capable of characterizing NC, at acceptable speed and reliability, to meet the industrial demands in a cost-effective way. Therefore, reliable characterization methodologies of $\mathrm{NC}$ and new standards are of paramount importance in ensuring reproducible research results and quality control specifications for present and future NC products and applications. Furthermore, the successful industrial use of NC products depends on critical parameters that are still being identified and studied. This review paper aims to identify some of the current drawbacks and limitations in NC characterization that hinder their commercial deployment. Moreover, important challenges related to characterization and new opportunities for future research in this field are addressed.

Keywords: Nanocellulose; Cellulose nanofibers; Cellulose nanocrystals; Characterization; Aggregationdispersion; Fibrillation degree; Industrial application; Standardization

Contact information: a: Department of Chemical Engineering and Materials, Complutense University of Madrid, 28040 Madrid, Spain; b: LEPAMAP Research Group, University of Girona, C/ Maria Aurelia Capmany, 61, 17003 Girona, Spain; *Corresponding author: ablanco@ucm.es

\section{INTRODUCTION}

Nanocellulose (NC) materials have unique properties and functionalities, due to their nanosize, morphology, and huge surface area, and these characteristics open many application areas that were once thought unbelievable for cellulose materials (Blanco et al. 2018; Dufresne 2019; Isogai 2020). The potential use of NC has expanded across a broad spectrum of high-performance material applications in different sectors as adhesives, cement, paper and cartonboard products, fluids, nanocomposites, films, cosmetics, paints, membranes, template for flexible electronic components, batteries, textiles, biomedical and tissue engineering scaffolds, food coatings, health care, etc. (Kargarzadeh et al. 2017; Kargarzadeh et al. 2018; Klemm et al. 2018; Balea et al. 2019; Barhoum et al. 2019; Dufresne 2019; Tarrés et al. 2020; Trache et al. 2020). Research and commercialization are driven by exceptional NC characteristics, such as high on-axis stiffness, sustainability, biodegradability, scalability, and mechanical reinforcement potential. Thus, NC is expected to be one of the most widely applied nanomaterials in the coming years, since its prices are expected to decrease drastically based on a competitive market (Miller 2019b; Nanocellulose Market 2019).

The latest forecasts show that NC products are of increasing interest. According to the Web of Science and considering "nanocellulose" as the search term, nearly 5300 papers have been published since 2006, starting with 2 in 2006 and with around 1000 per year 
since 2018; with a 10-fold increase in the last 7 years. Additionally, more than 750 patents have been published in 2019 (data from Espacenet). Thus, the global market for NC is expected to grow at a compounded annual growth rate (CAGR) of $18.4 \%$, reaching EUR 576.5 million by 2023 (MarketandMarkets ${ }^{\mathrm{TM}}$ 2018), although Biobased Market predicts a higher growth of approximately $30 \%$.

Currently, NC is mostly used in paper, board, and packaging (36\% of the demand), nanocomposites (25\%) and filtration products (19\%) (Miller 2019a,b). Moreover, new NC applications are arising as an environmentally friendly substitute for other particles in specific markets with high-volume applications (such as paper and packaging, construction, coatings and nanofilms, paintings, etc.) (Lindstrom et al. 2015; Osong et al. 2016; Vilarinho et al. 2018; Balea et al. 2019; Souza et al. 2020; Balea et al. 2020) and with high-added value applications (such as biomedicine, electronic and magnetic papers, flexible electronics, etc.) (Lin and Dufresne 2014; Klemm et al. 2018; Isogai 2020). Thus, the global production of $\mathrm{NC}$ is expected to increase from 2,500 to almost 35,000 Tons/year by 2030 (FutureMarkets 2019; Miller 2019b). This means a 14-fold increase in barely 10 years. Nevertheless, the forecast made by Resource Information Systems Inc. (RISI) estimated the global production of NC about 450,000 Tons/year by 2025 .

However, though NC offers a tremendous opportunity for re-inventing materials in several markets, it also poses many challenges and risks. According to the European Materials Characterization Council's (EMCC) in its "Roadmap for Materials Characterization," current challenges can be categorized in three types:

- Technical challenges as "advancement and valorization of characterization tools" and "digitalization and automation" due to the low speed and accuracy in the measuring of the main properties of NC suspensions and products. This calls for a shift from existing methods (indirect, time-consuming, off-line) to new, cheap, fast, in-situ, and robust technologies.

- Implementation and commercialization challenges such as "coordination and harmonization" and "characterization to support safety," related to the high price of nanomaterials per se and their related technologies (time- and resource-consuming), the lack of standards as well as the gaps in regulation and safety. Thus, a significant improvement is mandatory regarding industrialization and cost-effectiveness, including standards, good practice protocols and policy recommendations.

- Open innovation and open science challenges named "improved access to characterization capacities and capabilities", in terms of characterization and modelling.

It follows from these points that characterization methods of $\mathrm{NC}$ are a key factor to promote the introduction of $\mathrm{NC}$ into the market and to ensure an efficient commerce between suppliers and buyers. The aim of this review is to highlight the main drawbacks and limitations in the current characterization methods of NC. Moreover, major challenges and new opportunities for future research are also discussed.

\section{NANOCELLULOSE CHARACTERIZATION: DRAWBACKS AND LIMITATIONS}

During the last decade, a large number of methods and techniques for characterizing $\mathrm{NC}$ have been developed, and several research and review papers have been published 
related to this issue (Kangas et al. 2014; Moser et al. 2015; Desmaisons et al. 2017; Foster et al. 2018; Moser 2018). These characterization protocols provide detailed information about their dimensions (length, diameter, and aspect ratio), morphology, surface charge, surface chemistry, crystallinity, mechanical properties and rheological properties, among other parameters, for the two main nanoscale cellulose products: nanocrystalline cellulose (NCC) and nanofibrillated cellulose (NFC), which are also called in the literature as cellulose nanocrystals (CNC) and cellulose nanofibers (CNF), respectively.

Both NCC and NFC can be isolated from the same cellulose source as raw material, but their production process and properties are quite different, having a wide spectrum of different sizes, morphologies, and particular properties (Salas et al. 2014; Mondal 2017; Blanco et al. 2018). NCC are produced by specialized companies mainly by cellulose acid hydrolysis (Reid et al. 2017a; Trache et al. 2017), and they are light, highly stiff, with a rod-like morphology (width 5 to $10 \mathrm{~nm}$, length 50 to $500 \mathrm{~nm}$ ) and a high crystallinity (Habibi et al. 2010). On the other hand, NFC are mostly produced by paper manufacturers using a mechanical defibrillation (Tejado et al. 2012; Abdul Khalil et al. 2014) and they are light, flexible, present high aspect ratios of 20 to 220 (length $>1 \mu \mathrm{m}$, width 20 to 100 $\mathrm{nm}$ or 4 to $10 \mathrm{~nm}$, if they are highly fibrillated) and a great entanglement capacity (Tayeb et al. 2018). Moreover, different chemical and enzymatic pretreatments applied to the pulp, prior to mechanical nanofibrillation, are usually employed to favor fibrillation and reduce the energy demand, obtaining a wide range of NFC that differ in their properties compared to NCC and mechanically produced NFC (also referred to as microfibrillated cellulose "MFC") making them attractive in a variety of industrial applications. In general, NCC and NFC have high mechanical strength, transparency, and are chemically reactive (Missoum et al. 2013; Habibi 2014). Then, the properties of NC and, consequently, their characterization techniques strongly depend on their production process (mechanical, chemical, or biological), the cellulose source material (wood, pulp, recycled paper, bamboo, agro wastes, cotton, or other sources of biomass) and their final application (Tayeb et al. 2018).

In this scenario, there are many methods and techniques for characterizing NC. Researchers, companies, and industrial sectors must select the most suitable technique for determining a certain parameter. Additionally, they have to determine the level of characterization needed for a particular purpose or application, using the appropriate technique in each case. Table 1 summarizes the main properties and characterization techniques for NC identifying the most suitable ones for advanced research level and for industrial environment. Characterization methods performed at laboratory are usually complex, time-consuming and off-line; they involve high capital investment and wellqualified personnel. On the other hand, nano-characterization methods at industrial level must be simple, robust, less-time consuming or with the possibility to be adapted for online measurement.

Recently, Foster et al. (2018) provided a useful guide of the most suitable technique for determining a certain parameter. However, there are still some additional parameters that have been just identified as key for the successful use of NC, as for example the dispersion of the NFC network before application (Campano et al. 2018a). This is especially critical for market products. 
Table 1. Main Properties and Characterization Techniques for NC

\begin{tabular}{|c|c|c|c|c|}
\hline Property & Characterization techniques & Acronym & $\begin{array}{l}\text { Advanced } \\
\text { research }\end{array}$ & $\begin{array}{c}\text { Industrial } \\
\text { environment }\end{array}$ \\
\hline \multirow{9}{*}{$\begin{array}{l}\text { Size and } \\
\text { morphology: } \\
\text { - Length (L) } \\
\text { - Width (w) } \\
\text { - Diameter } \\
\text { - Aspect ratio (L/w) } \\
\text { - Average particle } \\
\text { size / size } \\
\text { distribution }\end{array}$} & Atomic force microscopy & AFM & $\mathrm{X}$ & \\
\hline & Scanning electron microscopy & SEM & $\mathrm{X}$ & \\
\hline & $\begin{array}{l}\text { Transmission electron } \\
\text { microscopy }\end{array}$ & TEM & $\mathrm{X}$ & \\
\hline & Optical microscope & OM & & $\mathrm{X}$ \\
\hline & Fiber analyzer & & & $\mathrm{X}$ \\
\hline & Fractionators & & & $\mathrm{X}$ \\
\hline & Gel point (for aspect ratio) & GP & $\mathrm{X}$ & $\mathrm{X}$ \\
\hline & Viscosity (for aspect ratio) & & $\mathrm{X}$ & $\mathrm{X}$ \\
\hline & $\begin{array}{l}\text { Light scattering techniques: } \\
\text { - Dynamic light scattering } \\
\text { - Depolarized DLS }\end{array}$ & $\begin{array}{l}\text { DLS } \\
\text { DDLS }\end{array}$ & $X$ & $\mathrm{X}$ \\
\hline \multirow{4}{*}{$\begin{array}{l}\text { Physical } \\
\text { properties: } \\
\text { - Crystallinity } \\
\text { (mainly for NCC) } \\
\text { - Degree of } \\
\text { polymerization } \\
\text { (DP) } \\
\text { - Specific surface } \\
\text { area (SSA) } \\
\text { - Density }\end{array}$} & $\begin{array}{l}\text { Crystallinity and dimensions of } \\
\text { cellulose crystals: } \\
\text { - X-ray diffraction } \\
\text { - Raman spectroscopy } \\
\text { - Infrared spectroscopy } \\
\text { - }{ }^{13} \mathrm{C} \text { nuclear X-ray diffraction } \\
\text { magnetic resonance } \\
\text { - Solid-state nuclear } \\
\text { magnetic resonance }\end{array}$ & $\begin{array}{l}\text { XRD } \\
{ }^{13} \mathrm{C} \text { NMR } \\
\text { ssNMR }\end{array}$ & $\mathrm{X}$ & \\
\hline & Viscosity method & & $\mathrm{X}$ & $\mathrm{X}$ \\
\hline & $\begin{array}{l}\text { Determination of SSA: } \\
\text { - N2 adsorption, Brunauer- } \\
\text { Emmett-Teller isotherms } \\
\text { - Congo Red method } \\
\text { - Small angle X-ray scattering }\end{array}$ & $\begin{array}{l}\text { BET } \\
\text { SAXS }\end{array}$ & $x$ & \\
\hline & $\begin{array}{l}\text { Network density (on } \\
\text { nanopapers): } \\
\text { - Air permeability (Vase de } \\
\text { Mariotte, Bendsen) } \\
\text { - Porosity (calculation from } \\
\text { basis weight and thickness) } \\
\text { - Transparency } \\
\end{array}$ & & $X$ & $\mathrm{X}$ \\
\hline \multirow{6}{*}{$\begin{array}{l}\text { Elemental } \\
\text { analysis (EA) }\end{array}$} & $\begin{array}{l}\text { Carbon hydrogen nitrogen } \\
\text { elemental analysis }\end{array}$ & $\begin{array}{l}\text { CHN } \\
\text { CHNS } \\
\text { CHNSO } \\
\text { CHNSOX }\end{array}$ & $x$ & \\
\hline & $\begin{array}{l}\text { Secondary ion mass } \\
\text { spectrometry }\end{array}$ & SIMS & $X$ & \\
\hline & X-ray photoelectron & XPS & $X$ & \\
\hline & Auger electron spectroscopy & $\mathrm{AES}$ & $\mathrm{X}$ & \\
\hline & $\begin{array}{l}\text { Energy dispersive X-ray } \\
\text { spectroscopy }\end{array}$ & $\begin{array}{l}\text { EDS (or } \\
\text { EDX) }\end{array}$ & $X$ & \\
\hline & $\begin{array}{l}\text { Inductively coupled plasma: } \\
\text { - Mass spectrometry } \\
\text { - Atomic emission } \\
\text { spectroscopy }\end{array}$ & $\begin{array}{l}\text { ICP-MS } \\
\text { ICP-AES }\end{array}$ & $X$ & \\
\hline Water retention & Water retention value & WRV & $\mathrm{X}$ & $\mathrm{X}$ \\
\hline
\end{tabular}




\begin{tabular}{|c|c|c|c|c|}
\hline Property & Characterization techniques & Acronym & $\begin{array}{l}\text { Advanced } \\
\text { research }\end{array}$ & $\begin{array}{l}\text { Industrial } \\
\text { environment }\end{array}$ \\
\hline \multirow{9}{*}{$\begin{array}{l}\text { Fibrillation degree } \\
\text { (for NFC) }\end{array}$} & Atomic force microscopy & AFM & $\mathrm{X}$ & \\
\hline & Scanning electron microscopy & SEM & $\mathrm{X}$ & \\
\hline & $\begin{array}{l}\text { Transmission electron } \\
\text { microscopy }\end{array}$ & TEM & $X$ & \\
\hline & $\begin{array}{l}\text { Optical microscope (for low } \\
\text { fibrillation degree) }\end{array}$ & OM & & $x$ \\
\hline & $\begin{array}{l}\text { Mechanical fractionation by } \\
\text { combination of sieves and } \\
\text { membranes }\end{array}$ & & $X$ & \\
\hline & Field/tube flow fractionation & & $\mathrm{X}$ & \\
\hline & Centrifugation & & $\mathrm{X}$ & $\mathrm{X}$ \\
\hline & $\begin{array}{l}\text { Transmittance by UV-vis } \\
\text { spectroscopy }\end{array}$ & & $X$ & $\mathrm{X}$ \\
\hline & Turbidity & & $\mathrm{X}$ & $\mathrm{X}$ \\
\hline \multirow{6}{*}{$\begin{array}{l}\text { Dissolved and } \\
\text { colloidal } \\
\text { substances } \\
\text { (amount and } \\
\text { quality) }\end{array}$} & Atomic force microscopy & AFM & $\mathrm{X}$ & \\
\hline & Scanning electron microscopy & SEM & $\mathrm{X}$ & \\
\hline & $\begin{array}{l}\text { Transmission electron } \\
\text { microscopy }\end{array}$ & TEM & $X$ & \\
\hline & $\begin{array}{l}\text { Gel permeation } \\
\text { chromatography }\end{array}$ & GPC & $X$ & \\
\hline & $\begin{array}{l}\text { Size-exclusion } \\
\text { chromatography }\end{array}$ & SEC & $X$ & \\
\hline & $\begin{array}{l}\text { High-performance liquid } \\
\text { chromatography }\end{array}$ & HPLC & $X$ & \\
\hline \multirow{5}{*}{$\begin{array}{l}\text { Surface charge } \\
\text { and chemistry: } \\
\text { - Surface } \\
\text { modifications } \\
\text { - Charge } \\
\text { determination }\end{array}$} & $\begin{array}{l}\text { Surface chemically modified by } \\
\text { adsorption: } \\
\text { - Fourier-Transform infrared } \\
\text { spectroscopy } \\
\text { - Elemental analysis }\end{array}$ & $\begin{array}{l}\text { FTIR } \\
\text { EA }\end{array}$ & $X$ & \\
\hline & $\begin{array}{l}\text { Surface chemically modified by } \\
\text { covalent bonding: } \\
\text { - Fourier-Transform infrared } \\
\text { spectroscopy } \\
\text { - Solid-state nuclear magnetic } \\
\text { resonance } \\
\text { - X-ray photoelectron } \\
\text { spectroscopy } \\
\text { - Elemental analysis }\end{array}$ & $\begin{array}{l}\text { FTIR } \\
\text { ssNMR } \\
\text { XPS } \\
\text { EA }\end{array}$ & $X$ & \\
\hline & Inverse gas chromatography & IC & $\mathrm{X}$ & \\
\hline & Conductimetric titration & & $\mathrm{X}$ & $\mathrm{X}$ \\
\hline & $\begin{array}{l}\text { Charge determination: } \\
\text { - Cationic demand } \\
\text { - Zeta potential }\end{array}$ & $\begin{array}{l}C D \\
Z P\end{array}$ & $X$ & $\mathrm{X}$ \\
\hline \multirow{2}{*}{$\begin{array}{l}\text { Rheology: } \\
\text { - Viscosity } \\
\text { - Yield stress } \\
\text { - Gel point } \\
\text { - Aspect ratio }\end{array}$} & $\begin{array}{l}\text { Low shear viscosity by } \\
\text { viscometers }\end{array}$ & & $X$ & $\mathrm{X}$ \\
\hline & $\begin{array}{l}\text { Gel strength, viscoelastic } \\
\text { properties by rheometers }\end{array}$ & & $X$ & $X$ \\
\hline
\end{tabular}




\begin{tabular}{|c|c|c|c|c|}
\hline Property & Characterization techniques & Acronym & $\begin{array}{l}\text { Advanced } \\
\text { research }\end{array}$ & $\begin{array}{c}\text { Industrial } \\
\text { environment }\end{array}$ \\
\hline \multirow{6}{*}{$\begin{array}{l}\text { Mechanical and } \\
\text { thermal properties }\end{array}$} & Tensile testing & & $\mathrm{X}$ & $\mathrm{X}$ \\
\hline & Flexural testing & & $\mathrm{X}$ & $\mathrm{X}$ \\
\hline & Compression testing & & $\mathrm{X}$ & $\mathrm{X}$ \\
\hline & Dynamic mechanical analysis & DMA & $\mathrm{X}$ & \\
\hline & Raman spectroscopic & & $\mathrm{X}$ & \\
\hline & Thermogravimetric analysis & TGA & $\mathrm{X}$ & $X$ \\
\hline \multirow[t]{2}{*}{ Other properties } & $\begin{array}{l}\text { Health characterization (i.e. } \\
\text { eye irritation, skin irritation, } \\
\text { genotoxicity, toxicokinetic } \\
\text { testing, systemic testing, } \\
\text { ecotoxicity...) }\end{array}$ & & $x$ & \\
\hline & $\begin{array}{l}\text { Safety characterization (i.e. } \\
\text { deflagration index...) }\end{array}$ & & $x$ & \\
\hline
\end{tabular}

At this moment, the quality and reliability of NC cannot be properly guaranteed, as there are no adequate technologies capable of providing fast and faithful characterization under industrial conditions. Moreover, current nano-characterization methods present some drawbacks and limitations, and they are based on off-line measurements carried out in laboratory facilities that require complex and time-consuming post-processing and analysis and involve high capital investment and highly qualified personnel. In addition, the absence of real-time characterization methods generates a critical delay in information gathering, which limits the implementation of monitoring and control routines in $\mathrm{NC}$ production processes. This section gives a summary of the main drawbacks and limitations for the characterization of NC.

\section{Commercial NC Products}

The industrial production of $\mathrm{NC}$ has turned to produce dried powders or concentrated suspensions to save costs (mainly shipping and storage) and to increase the shelf-life of NC products. For this reason, these dried or concentrated materials are intended to be dispersed back to their suspension form.

Although NCC can be purchased as concentrated suspensions (6 to $12 \mathrm{wt} \%$ ), they are usually commercialized as redispersible dried powders. NFC can be purchased as concentrated suspensions up to $25 \mathrm{wt} \%$ or as freeze/spray dried forms. However, drying technologies for NFC do not provide fully redispersible materials (Foster et al. 2018). Redispersion back to individual nanoparticles is crucial for their use (Campano et al. 2018a), but nowadays there is a lack of methodologies to assess the aggregation-dispersion degree of NC. In addition, current drying techniques (i.e. air drying, freeze-drying or spray drying) need to be further improved to prevent aggregation due to self-hydrogen bonding between NC particles (Peng et al. 2013).

Additionally, all these dried NC products hold approximately 2 to $5 \mathrm{wt} \%$ of residual moisture content, which increases the difficulty to use certain characterization techniques as, for example, the specific surface area (Foster et al. 2018). Although moisture can be removed by heating and vacuum pressure, NC will quickly reabsorb water from the atmosphere (Shrestha et al. 2017); such behavior is an important drawback in all characterization techniques that required a free-water ambient.

If NC products are in wet form, suspensions for laboratory testing should be stored in the refrigerator with some drops of bactericide to prevent microbial growth. The storage of sulfuric acid hydrolyzed NCC in the refrigerator is also mandatory to reduce self- 
catalyzed desulfation of the nanocrystals (Beck and Bouchard 2014). However, for toxicity analysis or biomedical applications, bactericidal agents should not be added to NC suspensions, and microbiological stability must be maintained by low temperature and/or low water activity, combined with a fast testing, which is an important disadvantage.

\section{Nanoscale Dimension, Morphology, and Structure}

In the field of $\mathrm{NC}$, the determination of the nanoscale dimensions of the products is crucial to ensure their quality, to extend the knowledge on their production and application, to compare different products available on the market and to facilitate their industrial implementation.

Characterization by microscopic methods such as scanning electron microscopy (SEM), transmission electron microscope (TEM), and atomic force microscopy (AFM) is commonly used by the research community to determine size and morphology of NC (Marway 2017). Many other techniques based on light interactions, electrical properties, sedimentation, sorting, classification and polymer, and dye adsorption could be also used to the determine size of the nanoparticles (Inglesby and Zeronian 2002; Fraschini et al. 2014; Espinosa et al. 2016; Mao et al. 2017). These models work well when describing spherical scatters (Bhattacharjee 2016), but for rod-like and acicular particles the contribution of rotational diffusion is present. Thus, only hydrodynamic "apparent particle size" can be determined, which has a limited value (Ureña-Benavides and Kitchens 2012). $\mathrm{NC}$ have high aspect ratios with different parallel and perpendicular translational diffusion constants to the particle axis, such that the dynamic light scattering (DLS) values are not directly correlated to the particle length or cross-section. Moreover, as translational diffusion of particles is a function of orientation, distributions cannot be linked with particle size distributions. Therefore, although light scattering techniques are faster than microscopy, their simplifying assumptions are especially not accurate in the case of nanofibers or nanocrystals particles (Fraschini et al. 2014).

Microscopy techniques provide sufficient nanometer scale resolution capabilities for NC imaging and nanoparticle size. Thus, some dimensions can be determined, depending on the particle shape. The accuracy of these techniques is often related to the shape of the particle and its physicochemical characteristics (i.e. chemical composition, heterogeneity, topography, surface charge density, dispersing medium, etc.) (Fedotov et al. 2011). Although AFM has great potential in nanoscience, several limitations and drawbacks are associated with the technique (Dufrêne 2002; Marway 2017): (i) expensive equipment and qualified personnel; (ii) high probability of error during sampling and sample preparation; (iii) difficulty to determine nanofibers' length; (iv) time consuming methodology (off-line technique), that can take more than 2 hours from preparation of the sample to the analysis of the image; (v) non-reliable measurements: accuracy between 50 and $60 \%$, depending on the sample, as a result of lacking correlation with other properties; 30 to $40 \%$ precision because suspensions are strongly affected by thixotropic; and (vi) very low reliability, since multiple samples must be taken and tested at different conditions.

Among microscopy techniques, TEM is the most used microscopy technique for the characterization of nanoparticles due to the high spatial resolution compared with SEM (Foster et al. 2018). Although TEM images can lead to satisfactory determination of the NC size (Kaushik et al. 2014, 2015), the sample preparation and requirements for skilled operation are also difficulties associated with the technique. Recently, Mattos et al. (2019) have demonstrated that negative-contrast SEM enables easy and fast imaging while maintaining a good contrast. Another disadvantage of the microscopy techniques is that the 
comparison of results between different techniques is not straightforward. Because SEM is faster and easier to use than AFM, Mattos et al. (2019) correlated dimensions for negativecontrast SEM (width/length) and AFM (height/width) to better describe the sample by only using the negative-contrast SEM technique. Furthermore, the small amount of sample and the limited field of view at very high magnification used in microscopy have prompted questions about how representative are the results obtained from these techniques (Ang et al. 2020). Microscopy techniques are also time-consuming, when one considers the steps of delicate sample preparation, observation of the sample, and analysis of the images (Kangas et al. 2014; Osong et al. 2016). Moreover, the concentration of sample used for microscopy is crucial to determine the size of nanoparticles but it depends on many factors such as the type of NC (NFC or NCC), their production process, their cellulose source and the surface charge, among others. If microscopy images are taken at excessive sample concentration, NFC entanglement or NCC agglomeration may hinder the analysis of the images. By contrast, extremely diluted samples will lead to non-representative images due to the low presence of nanoparticles in the analyzed area (Ang et al. 2020). It is important to notice that in the case of nanofibers only in few cases can microscopy techniques provide satisfactory determination of the length due to the size of the nanofiber in comparison with the magnification of the microscopy image. In addition, high energy in the electron beam may burn the sample at high magnification. Then, obtaining relevant images for statistical measurements can be challenging.

From the literature, the determination of NC dimensions from image analysis has been reported using different methods, with different levels of complexity that vary from a simple and basic measurements of few nanoparticles from an image to a complex statistical analysis performed of all nanomaterial present in a large quantity of microscopy images (Ang et al. 2020). However, more research is needed in this field to determine the number of nanofibers or nanocrystals to be measured in an image to obtain an accurate distribution, the total number of microscopy images to have a reliable result, the effect of using different operators when microscopy images are manually analyzed, or how to prepare the sample if the dispersion-agglomerate state of the suspension is the purpose of the study. Recently, Ang et al. (2020) and Campano et al. (2020a) have studied some of these unknown aspects to improve microscopy characterization of NC. Campano et al. (2020a) have developed a new microscopy approach to ensure that the bulk morphology of NC suspensions is not altered in the course of the sampling process required for microscopic TEM image acquisition. On the other hand, Ang et al. (2020) have found that when the operators have to manually select 100 representative fibers in a microscopy image, they showed consistent bias towards larger fibers, which led to inaccurate results. A more promising approach is to analyze all fibers within a reduced area within an image.

Despite all research efforts, there are no effective and standard methods for measuring the size of NC products or the fibrillation degree in the case of NFC. On the other hand, no method has been described to evaluate dispersion-aggregation state of $\mathrm{NC}$ at industrial scale.

In several high-temperature applications, such as electronic devices, fire-retardant coating additives or melt compounded nanocomposites, thermal stability of NC is crucial to ensure an appropriate performance of the NC-based products. NC has been reported to show lower thermal stability than the lignocellulosic fibers they are made from, especially if NC has been obtained by means of chemical methods (i.e. TEMPO-mediated oxidation or acid hydrolysis) (Lichtenstein and Lavoine 2017). In several thermogravimetric analysis (TGA) studies, dried TEMPO-oxidized NFC have exhibited a degradation temperature 
about $50{ }^{\circ} \mathrm{C}$ below the corresponding to its untreated raw material, being of the magnitude of 222 and $275{ }^{\circ} \mathrm{C}$. This lower degradation temperature may be attributed to the decarboxylation of the carboxyl groups from the NFC surface, as well as to the large specific surface area (SSA) exposed to heat (Fukuzumi et al. 2010). Indeed, the dependence between the carboxyl content and the degradation temperature has been previously glimpsed, as well as the char content at $500{ }^{\circ} \mathrm{C}$, which may account for 25 to $30 \mathrm{wt} \%$. The presence of such residue has been attributed to the formation of a carbonaceous layer at the surface of the NFC due to the presence of carboxylic groups (Tarrés et al. 2017). Acid hydrolysis, especially conducted with sulfuric acid, also has negative effects on thermal stability of NCC due to the presence of surface sulfate groups, which lower the activation energy of decomposition. In addition, the char content at $500{ }^{\circ} \mathrm{C}$ has been also reported to be high and attributed to the dehydration effect of sulfate groups (Jiang and Hsieh 2013). Regarding the SSA, some studies have revealed that degradation temperature decreases at high exposed surface to heat, which may also limit the use of mechanically fibrillated NC in some applications (Velásquez-Cock et al. 2016). Another interesting approach are NC suspensions, where the presence of water or other solvents may prevent thermal degradation. From this point of view, NC suspensions in water have been reported to be more effective than guar gum and xanthan as drilling fluids, where temperature may be increased, although the suspension may start its degradation from $110{ }^{\circ} \mathrm{C}$ (Heggset et al. 2017). In addition, temperature has been reported to not have significant effects on rheological properties NFC, although it may affect the dispersion and flexibility of NCC, leading to changes in suspension viscosity (Hubbe et al. 2017).

In terms of characterization, TGA provides valuable information on the degradation processes of NC. However, as in the case of cellulose, degradation mechanisms are still uncertain, as two main pathways have been proposed in the literature: (i) dehydration of cellulose, which leads to further char content, and (ii) depolymerization of cellulose to levoglucosan, which may form bio-oil by further thermal degradation. Apparently, the first pathway may occur at slow heating rates, ranging from 1 to $5 \mathrm{~K} / \mathrm{min}$, while the second one is proposed for faster pyrolysis above $5 \mathrm{~K} / \mathrm{min}$ (Pouwels et al. 1989; Lin et al. 2009).

\section{Suspensions of NC: Surface Chemistry and Dispersion-aggregation State}

Fourier-transform infrared spectroscopy (FTIR) can be considered as a key technique to characterize the surface chemistry of $\mathrm{NC}$ and many studies have employed FTIR for determining specific groups and bonds on the surface of NC (Panaitescu et al. 2018; Sahlin et al. 2018) and/or to evaluate the effectiveness of grafting chemical reactions (Xiao et al. 2018; Vadakkekara et al. 2020; Wang et al. 2020). The surface chemistry of $\mathrm{NC}$ is also linked to its colloidal stability, rheological properties, and interactions with other chemical species. For sulfuric acid hydrolyzed NCC, it has been shown that there is a reduction in the sulfate half ester groups over time. Consequently, there is a decrease in their surface charge, colloidal stability, and $\mathrm{pH}$ of the suspension (Beck and Bouchard 2014) and, consequently, their application could be also compromised. Therefore, actual off-line measurements of NC should be replaced by faster and on-line characterization techniques to evaluate how properties are changing with the time to fulfil their industrial requirements.

Neutralized NFC and NCC suspensions in the sodium-salt form can be totally or partially dispersed after drying (Beck et al. 2012; Missoum et al. 2012). However, drying of the acid-form of NCC results in aggregates that will not disperse even with intense sonication due to strong particle-particle interactions; this behavior has been attributed to 
hydrogen bonding and attractive van der Waals forces (Reid et al. 2016, 2017b). NFC are less commonly dried due to their inherently entangled structure, which leads to difficulties in dispersing them; however, new drying processes, dispersant agents and appropriate surface modification methods have been investigated to improve the dispersion performance of NC and, as consequence, to commercialize more dispersible forms of dried NFC (Eyholzer et al. 2010; Butchosa and Zhou 2014; Takaichi et al. 2014; Chu et al. 2020). Many researchers have discussed the importance of dispersion and uniformity of NC on nanocomposite performance (Campano et al. 2018a). During the last decade several methods have been reported to evaluate dispersion of $\mathrm{NC}$ such as dynamic light scattering (DLS), zeta potential (ZP), turbidity, self-assembly, and shear birefringence (Foster et al. 2018).

DLS measures the time-dependent fluctuations in scattered light intensity of particles undergoing Brownian motion (Xu 2015; Bhattacharjee 2016). For spherical particles that have a single and constant rate of diffusion, the intensity fluctuations are related to the particle size. However, since NC particles have high aspect ratio, rod or fibrillated materials with differing translational diffusion constants parallel and perpendicular to the particle axis, the values obtained from DLS cannot be directly linked to the particle length or cross-section of the particles. Therefore, DLS gives a hydrodynamic "apparent particle size" that can be used to determine aggregationdispersion of NC suspensions and compare results from different samples if the same DLS equipment, sample preparation protocol and measuring methodology are employed in all NC samples (Foster et al. 2018). Other researchers have also reported the use of other light scattering methods to assess the dispersion of NC suspensions such as nanoparticle tracking analysis (laser light source) or static light scattering (Ureña-Benavides and Kitchens 2012; Fraschini et al. 2014). Moreover, reliable data from DLS are also linked to fully dispersed NCC suspension (around $0.025 \mathrm{wt} \%$ ), which is an important limitation of this technique. Less concentrated samples will promote multiple peaks and inaccurate data, reducing the "apparent particle size" due to the low scattering count; and highly concentrated samples will promote particle agglomeration, which may lead to larger "apparent particle sizes" (Reid et al. 2017a). On the other hand, DLS techniques are not suitable for measuring NFC because of the flexibility and very high aspect ratios of NFC particles (Foster et al. 2018). Another important limitation of DLS technique is that the presence of salts alters the double layer and mobility of particles affecting the "apparent particle size" (Bhattacharjee 2016). Therefore, researchers are encouraged to combine results from DLS with other techniques such as microscopy measurements (Reid et al. 2017a)

$\mathrm{ZP}$, which is related to the surface potential and surface charge density, could be used to assess NC colloidal stability. ZP can be measured using an electrophoretic mobility analyzer in which the electrophoretic mobility could be converted to ZP using the Henry equation with Smoluchowski or Huckel approximations. In general terms, suspensions with absolute $\mathrm{ZP}$ values above $20 \mathrm{mV}$ are considered stable. Common values for NCC are -20 to $-50 \mathrm{mV}$ and $\mathrm{ZP}$ values for NFC can be near to $-60 \mathrm{mV}$, depend on the degree of oxidation (Foster et al. 2018). Due to the high aspect ratio and the high surface charge density of $\mathrm{NC}$, the assumptions inherent to Henry's equation are often not met, and thus $\mathrm{ZP}$ should not be considered as a quantitative reliable measurement. Moreover, $\mathrm{ZP}$ is affected by the $\mathrm{pH}$, temperature and the presence of salt and impurities in the suspension. Therefore, all the above factors should be controlled to obtain reliable data, and these requirements place an important limitation of this technique (Foster et al. 2018). Turbidity and shear birefringence have also been proposed as a methods to estimate the aggregation- 
dispersion of the nanoparticles, but the changes in turbidity can be linked to multiple physical phenomena and kinetic effects that are not solely related to nanoparticle aggregation and shear birefringence is a qualitative measurement not valid above a threshold aggregate size (Foster et al. 2018).

As such, the research community, companies, and associations linked to the NC sector such as FPInnovations, Natural Resources Canada/Canadian Standards Association, USA's Nanotechnology Initiative, and TAPPI, have pointed out that reliable dispersion of $\mathrm{NC}$ in aqueous and non-aqueous media and better methods to assess dispersion must be developed.

\section{CHALLENGES AND OPPORTUNITIES FOR NANOCELLULOSE CHARACTERIZATION}

The absence of fast and reliable NC characterization technologies leads to a series of problems that are hindering the deployment of the $\mathrm{NC}$ at an industrial level, due to the financial risks associated to the uncertainty of the NC performance, such as: (i) being over or under the targeted concentration of $\mathrm{NC}$ to achieve the desired properties of the solution, then being poorly efficient; (ii) wrong distribution or inadequate properties of the NC, which contribute to undesired or poor features of the final product; and (iii) safety and environmental concerns as a result of the lack of knowledge and control. Figure 1 summarizes the main challenges and opportunities in this field.

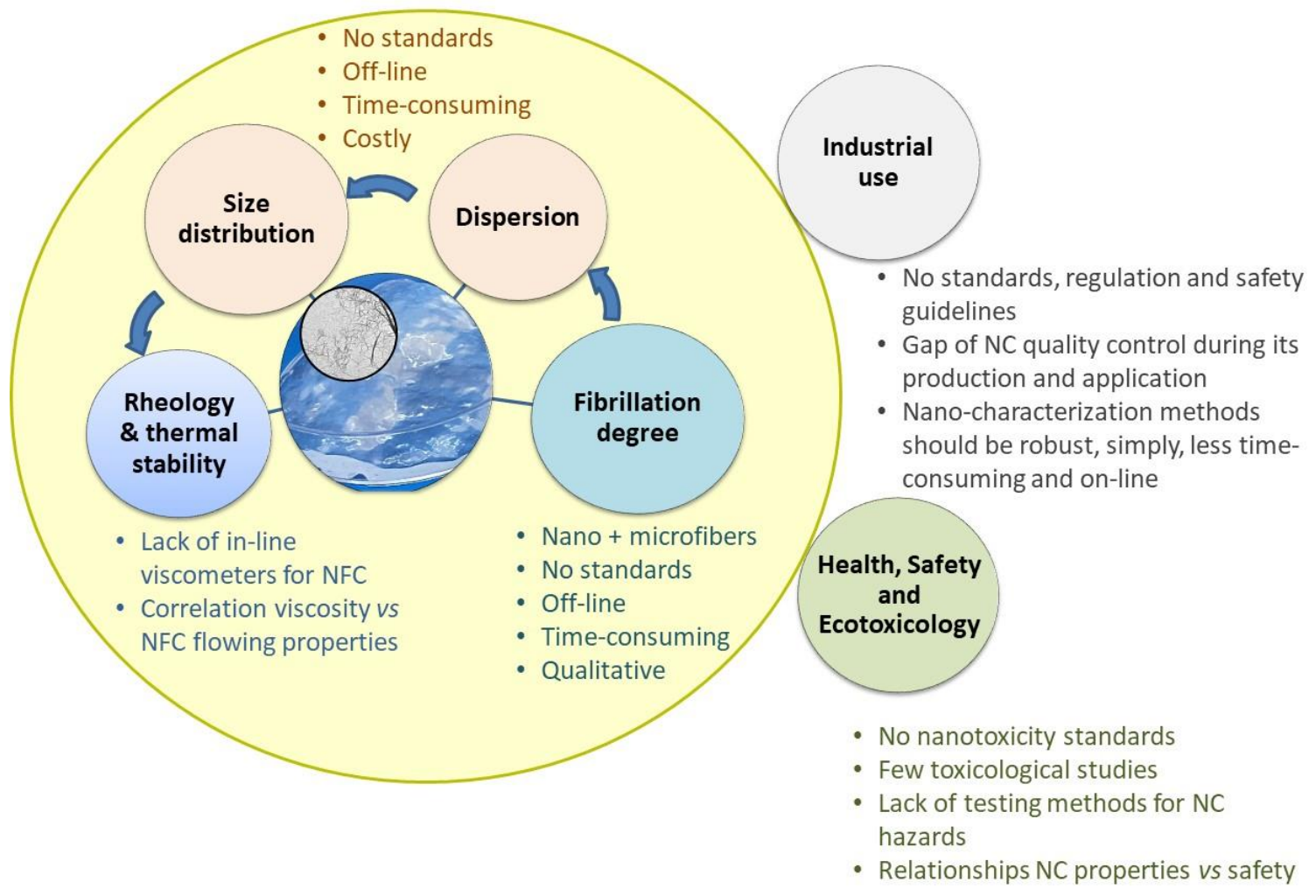

Fig. 1. Challenges and opportunities for NC characterization 


\section{Size Distribution and Aggregation-dispersion State}

As mentioned above, for the intensification of industrial production of market NC, it is necessary to dry or concentrate both NCC and NFC primarily to save costs on shipping and storage, and to increase the shelf-life of the materials. Since NC are produced in suspension or redispersed from dry into suspension for its use, it is crucial for their use (Campano et al. 2018a) to have quantitative measurements to assess their size and state of aggregation/dispersion.

Therefore, precise protocols and techniques for characterizing dispersion, particle size and morphology are clearly mandatory to guarantee a consistent production and application of high-quality NC products. Usually, particle size measurement techniques provide different but complementary information on the dimensions, morphology, aggregation-dispersion degree of particles. However, there are no standard methods for size or dispersion determination of NC products. Moreover, the comparison of data obtained from different techniques is very tricky to establish. In addition, the industrial instruments are limited to the microscale nature and most of techniques to determine dimensions of NC are off-line, time-consuming and high cost.

Gel point analyses have been recently developed for NFC to estimate their aspect ratio (Sanchez-Salvador et al. 2020). New attempts to use it to analyze the nanofiber network structure and their aggregation-dispersion degree are being carried out. Moreover, a new approach to evaluate the aggregation state of NCC suspensions has been recently developed based on the analysis of TEM images through the clustering of the different types of NCC aggregates into five groups according to maximum Feret diameter (MFD), elongation, circularity, and area (Campano et al. 2020b). However, both methods are still time consuming, and faster techniques are required.

Recent developments include multi-angle scattering and depolarized DLS (DDLS). The new DDLS prototypes allow the unambiguous determination of rotational and translational diffusions coefficients of nanorods in suspension and can give indications of the shape of the NCC (Nixon-Luke and Bryant 2019). A more sophisticated analysis of light scattering techniques data could provide deeper insight for rod-like particles to obtain absolute values. In addition, IR thermography could be used complementarily to correlate the evolution of thermographic images with aggregation state, size distribution and concentration (Ciampa et al. 2018) and focus beam reflectance measurement (FBRM) for monitoring the NCC aggregation kinetic under different conditions (Blanco et al. 2000).

\section{Fibrillation Degree}

NFC are produced by mechanical treatments under high shear to fibrillate the cellulose raw material. NFC are flexible fibrils of typical length $>1 \mu \mathrm{m}$, width 20 to 100 $\mathrm{nm}$ and aspect ratios of 10 to 100, where the surface chemistry, charge, and particle morphology are determined by the pretreatment, mechanical shear process, and cellulose source. Mechanical, chemical, or enzymatic pretreatments favor fibrillation and reduce energy consumption. For example, with TEMPO-mediated oxidation highly fibrillate NFC with widths of 4 to $10 \mathrm{~nm}$ are obtained after fibrillation. In most cases the final product is a mixture of micro- and nano-fibrils, and the final effect of $\mathrm{NC}$ in certain applications is not always correlated to higher fibrillation degrees (Balea et al. 2016; Campano et al. 2018b), while in others it is (Patiño-Masó et al. 2019; Tarrés et al. 2019). Thus, it is important to quantify their size and state of aggregation but also their fibrillation degree. The fibrillation degree is a measure of the deconstruction of the fiber wall structure into cellulose nanofibrils. Current methodologies (mainly AFM and SEM) are off-line and 
subjective methods that are time consuming and may provide a wrong description of the material.

The quantification of the fibrillation degree could be based on an optical approach that has been defined as multiscale characterization (MSC) (Chinga-Carrasco et al. 2011; Chinga-Carrasco 2013; Chinga-Carrasco et al. 2014). This method focuses on the translucency of $\mathrm{NC}$ suspension and the amount of residual fibers (fines, fiber fragments). The fraction of residual fibers is reduced and the translucency increases as the pulp is passed through a high-pressure homogenizer. The reduction of detected residual fibers and the increase in translucency is an indication of the production of NFC (diameters $<100$ $\mathrm{nm})$.

Currently, there are some fiber analyzers that are used off-line, for quantification of fiber morphology (especially length, diameter, aspect ratio, degree of polymerization, specific surface and gel transmittance). Hence, there exists no technology that can model the morphology of NFC based on simple and rapid micro-scale measurements during NFC production.

\section{Rheology and Thermal Stability}

NC rheology has been widely studied at laboratory scale (Hubbe et al. 2017) to determine concentration, aspect ratio, and surface functional group density (Jowkarderis and van de Ven 2014; Li et al. 2015; Colson et al. 2016). Though many aspects can be addressed in terms of well-known concepts and models, some of the most interesting issues for the industrial production, related to the high NFC aspect ratio, involves irreversible mechanisms, such as entanglement and rupture of network structures. Therefore, further studies are required on the detailed structure of floc fragments obtained after the breakage of NFC gels that have been stressed or strained beyond their reversible limits.

In-line viscometers are widely used in industry (water processing, food industry, cosmetics, plastics, etc.), and specifically in the paper industry for regular cellulosic fibers. However, the use of in-line viscometers for NFC characterization has not been developed, nor it is the correlation between viscosity and NFC flowing properties. Therefore, developing methods to rapidly tune the rheological properties of $\mathrm{NC}$ suspension for different processing is of great interest for both laboratory research and industrial application (Wang et al. 2019). Rheological analysis of the shear-dependent viscoelastic response could be effective for evaluating the contribution of NFC properties such as concentration, particle size, morphology, and surface functionality to processability and quality of dispersion. In addition, the change in apparent viscosity during pretreatments and fibrillation processes could be also useful for monitoring and control.

Researchers have acquired considerable knowledge on the characterization of NFC at laboratory scale, but only few relationships between properties can be established (Shinoda et al. 2012; Tanaka et al. 2014; Li et al. 2015). The definition of correlation tests of different types of NFC (at different temperature, shear rate, and consistencies) related to microscopy images and NFC aggregation will be the key to ensure the successful implementation of this technique, avoiding the need of AFM.

The thermal stability of dried NC structures (i.e., films or aerogels) requires further research for several purposes. On the one hand, there is a clear need of obtaining films with higher degradation temperatures to make them more competitive to plastic products, recovering at least the original thermal properties of raw materials. This could be achieved by means of developing high-performance NC using enzymatic or mechanical methods, where surface chemistry is not modified. On the other, improvements on thermal stability 
could be of interest for nanocomposites production and processing, where large residence times are required to remove water and prevent $\mathrm{NC}$ agglomeration within the matrix. Overall, the improvement of thermal stability of $\mathrm{NC}$ with equivalent characteristics to those obtained by means of chemical methods may necessarily encompass the development of competitive NC with enzymatic and/or mechanical methods, although the negative effect of large SSA is presumably unavoidable. In any of the abovementioned cases, the degradation mechanism needs to be further understood in order to find strategies that may prevent NC degradation at low temperatures.

\section{Process-adapted Measuring Tools: Manufacturing and Engineering Tools for the Industrial Application of NC}

Current nano-characterization methods are based on off-line measurements performed in laboratory facilities; they generally require complex and time-consuming post-processing and analysis and involve high capital investment and highly qualified personnel (European Commission 2018). Furthermore, results of industrial trials are in many cases unexpected, raising concerns among industrial stakeholders. Hence, the use of characterization technologies not suitable for industrial production lines is hindering the real potential of $\mathrm{NC}$.

Therefore, NC characterization is essential for monitoring production batches, adequately describing the product, providing essential information for downstream product formulation and total quality assurance to customers. Thus, being able to characterize NC as they flow though the production line and become sellable products is essential for their success, facilitating optimization, managing errors, minimizing unpredictable results, and providing confidence. The use of on-line industrial equipment's, such as turbidity meter sensors, to characterize NC could be a suitable strategy to support the development and operation of continuous manufacturing process making significant progress towards industrial application of NC. Prior laboratory attempts have reported the possibility to estimate the width of NFC based on the turbidities of their water dispersions (Shimizu 2016). The results showed that width values of NFC (range from 2 to $10 \mathrm{~nm}$ ), calculated from turbidity measurements, exhibit a good correlation with their thicknesses determined by AFM. It becomes apparent that particles below a certain size are not able to scatter light; therefore, a decrease in light scattering and an increase in the transmittance can be used to monitor and control the manufacturing process of NFC. Moreover, it is possible to correlate turbidity and transmittance to the degree of fibrillation (Moser et al. 2015). Moser et al. (2015) have compared different characterization techniques for monitoring the production of NFC at industrial scale. They found that centrifugation, turbidity, and transmittance measurements could give reliable data to evaluate the entire manufacturing process. Moreover, transmittance has been reported as the most appropriate measurement for the quality control routine of NFC because of its simple operation, fast analysis, and low cost (only a spectrophotometer equipment is needed).

Furthermore, there are no measuring standards for NC products, nor regulation or safety guidelines (Foster et al. 2018). NC properties, including their stability over time, are of critical importance for various industrial unit operations, such as pumping, mixing, storage, application, and filtering, as well as for the quality improvement of the final products. Considering that not all $\mathrm{NC}$ ventures have been successfully deployed and the high investment required for full commercialization, the gap of NC quality control during its production and application must be filled in to develop sound value propositions. 
On the other hand, the diffusional properties, mainly gas permeability coefficient and nano-mechanical properties, specifically Young modulus, hardness, yield stress, and strain hardening coefficient are the key parameters that need to be characterized for the optimal use on NCC and NFC-based products. In general, the entangled structure and the high aspect ratio of NFC-based products provide a tortuous diffusion path for gas molecules to permeate through the film (Österberg et al. 2013; Peresin et al. 2017). Additionally, the gas diffusion in a NC film occurs mainly through the non-crystalline part. Therefore, the crystallinity degree of NC films affects the gas permeability coefficient, such that lower coefficient values are achieved in higher crystallinity NC products. This occurs because the crystalline regions obstruct the diffusion of the gas molecules and increase the length of the path that they have to travel through the film (Nair et al. 2014). Currently, dynamic indentation is the most promising technology to determine the mechanical properties. The first dynamic indentation tests were performed at the beginning of the 90's. This technique, named CSM for "Continuous Stiffness Measurement", consists of adding a small oscillation amplitude to the load signal (Li and Bhushan 2002). Analyzing the dynamic response of the system, the storage modulus and the loss modulus of the material can be obtained. The main advantage of this technique is that the mechanical properties of the material (elastic modulus, loss modulus, hardness) are measured not just at one point on the load-displacement curve, but as a function of the entire penetration depth. This is very useful for thin film characterization. The dynamic method can also be used to extract the viscoelastic properties of polymers, or to perform repetitive loading of a surface.

Recent developments include efforts to improve the accuracy of mechanical properties measurements, especially in difficult experimental conditions. For example, a new method using the dynamic mode was proposed to measure more precisely the properties of rough samples. Another method, using the second harmonic of the dynamic signal, was developed to improve the measurement of properties at very small indentation depths. The dynamic mode was also used to measure the creep of the materials by compensating for thermal drift. Therefore, the dynamic mode is crucial in nano-mechanical testing for understanding the mechanical properties of thin films or graded materials. To date, the frequencies of dynamic testing have been limited to $\sim 200 \mathrm{~Hz}$. The fatigue and high strain rate performance of small volumes of thin products are highly relevant to a large number of technological applications. As such, many techniques (Kraft and Volkert 2001) have been developed for investigating fatigue deformation of thin films: thermal cycling of films on substrates, tensile testing of free-standing films and films on substrates, multicycle indentation, bulge testing, and micro beam bending. Except for dynamic micro beam bending (Burger et al. 2011a; Burger et al. 2011b), most of these test methods are limited to lower strain rates $\left(10^{-2} \mathrm{~s}^{-1}\right)$ and cycling rates.

Moreover, the expansion of the NC industry strongly depends on the advance of characterization and modelling techniques, since these protocols are the key to advance in both NC industrial production and their optimal utilisation in different applications (Lengowski et al. 2016; Zhou et al. 2018).

\section{Health, Safety and Ecotoxicology}

Nanomaterials, which have nanosized dimensions and large surface area, have high reactivity and potential effects on natural systems. As they can have a negative biological impact, their toxicological risks must be established. An accurate description of the product in terms of dimensions, chemistry and toxicity is also mandatory. Therefore, potential end- 
users of $\mathrm{NC}$ also need to know how these materials may impact health and environment and, consequently, evaluate which regulations are potentially impacted.

In recent years, several review papers have determined the possible toxicological effects of NC through their characterization (Roman 2015; Endes et al. 2016; Lie et al. 2017; Seabra et al. 2018). Roman (2015) reviewed the toxicity of NCC, finding a lack of adverse health effects in oral and dermal toxicity and a discordant results when pulmonary and cytotoxicity studies are carried out. The importance was noted of a detailed characterization of the sample because toxicity of NCC is highly influenced by their physicochemical properties, primarily their dimensions, aggregation degree, and surface chemistry. Furthermore, NFC and NCC have different dimensions and morphologies, which hinders a comparison of the different toxicological studies. Apart of a careful sample characterization, it is critical to exclude contaminants during testing, such as endotoxins or toxic chemical agents. Control experiments are needed, from which NC material has been removed. Such steps are crucial for a better understanding of the potential adverse health effects of NCC (Roman 2015).

Together with the physical and chemical characteristics of NC, other considerations and analysis also need to be addressed to evaluate the biological impact of NC. These include the type of biological test system studied (i.e. fibroblasts, epithelial cells, endothelial cells, etc.), the test designed to assess cytotoxicity, the inflammatory response, the oxidative stress status of the biological system studied, or the evaluation of genotoxicity (Endes et al. 2016). For example, the cytotoxicity of NC has been determined by many different testing methodologies, which include 3-(4,5-dimethylthiazol-2-yl)-2,5diphenyltetrazolium bromide (MTT) assay, (2,3-bis-(2-methoxy-4- nitro-5-sulfophenyl)2H-tetrazolium-5-carboxanilide) (XTT) assay, 5-bromo-20 -deoxyuridine (BrdU) assay, neutral red solution N6264 Sigma (NR) cytotoxicity procedure, observation the morphology of the biological test system with light microscopy, evaluation of apoptosis/necrosis or cell-cycle via flow cytometry, among others (Alexandrescu et al. 2013; Endes et al. 2016). Since specific nanotoxicity standards are not yet delivered by ISO, some authors used the standard cytotoxicity test methods ISO 10993-5 that covers tests that assess membrane integrity, mitochondrial activity and DNA proliferation (Alexandrescu et al. 2013).

Moreover, life-cycle assessment (LCA) studies of NC are also needed to identify and analyze possible high and low risk scenarios and, therefore, evaluate the potential risks of NC towards human health and the environment (Endes et al. 2016). Although some LCA analysis have suggested that the inhalation of $\mathrm{NC}$ would be the main exposure route for humans, more studies about the exposure concentrations or doses along the different stages, from NC production to customer use, are also required (Shatkin and Kim 2015; Endes et al. 2016). Recently, studies have also quantitative determined the environmental release and risks of NC through the use of probabilistic material flow and environmental risk assessment models (Stoudmann et al. 2019).

Nevertheless, there has been a limited number of toxicological studies for NC products in comparison with other topics such as production, characterization, or application of NC. Although most of these toxicological studies found that NC are safe and nontoxic, other researchers have demonstrated adverse health effects (Roman 2015; Camarero-Espinosa et al. 2016), which causes uncertainty regarding future regulations to assess potential health risks. 
In summary, there is a lack of specific testing methods for $\mathrm{NC}$ hazards and standards to characterize their biological behavior and to develop relationships between physicochemical NC properties and safety.

\section{Standardization}

In general terms, international standards have the potential to bring many benefits for the private and the public sectors and consumers. For the private sector, the main benefits of the standardization include: reduction in production and transaction costs; increased market opportunities; competitive positioning; and improved risk management. In addition, the public sector also benefits from standardization in several ways, such as: a basis for regulation; efficient regulation through participatory processes; and contribution to socio-economic development. Finally, consumers can benefit substantively from the use of standards, namely: consumer involvement; consumer safety; and sustainable development (ISO 2019). Therefore, international standards for NC are a key factor to remove trade barriers, harmonize research and development activities, and contribute to develop regulations by national and international bodies.

The strongest efforts to develop standards for $\mathrm{NC}$ are being undertaken by International Organization for Standardization (ISO), the Technical Association for the Pulp and Paper Industry (TAPPI), and the Canadian Standards Association (CSA) group. Table 2 summarizes the main standards for $\mathrm{NC}$ which includes the organism that belongs to, the current status of the standard (published or under developed) and their scope of application. ISO standard development activities concerning NC are carried out within two technical committees (TC): TC 6 (Paper, board and pulps), which scope includes also cellulose nanomaterials, and TC 229 (Nanotechnologies). Currently, four ISO/TC 229 and one ISO/TC 6 standards for NC have been published: TS 20477:2017 (Standard terms and their definition for cellulose nanomaterial); TS 16195:2018 (Specification for developing representative test materials consisting of nano-objects in dry powder form); TR 19716:2016 (Characterization of cellulose nanocrystals); TR 12885:2008 (Health and safety practices in occupational settings relevant to nanotechnologies); and 21400:2018 (Determination of cellulose nanocrystal sulfur and sulfate half-ester content). Moreover, five other ISO standards are under development (Table 2).

CSA Group published in 2012 the first edition of CSA Z12885 (Nanotechnologies - Exposure control program for engineered nanomaterials in occupational settings) based on ISO/TR 12885 and additional guidance to reflect Canadian practices and safety considerations. In 2014, CSA Group published the Canada's first national standard on cellulosic nanomaterials (CSA Z5100, Cellulosic nanomaterials-Test methods for characterization), which provides over 20 test methods to identify and characterize NC to encourage their introduction into global markets. Two additional CSA standards (Z5200 and Z5300) have also recently published (Table 2 ).

Since 2006, each year, the TAPPI NanoDivision hosts the International Conference on Nanotechnology for Renewable Materials. This conference provides a forum that delivers exceptional technical value, networking opportunities, and industry knowhow for participants working in research, development, or deployment of renewable nanomaterials. 
Table 2. Summary of ISO and CSA Standards for NC

\begin{tabular}{|c|c|c|c|c|}
\hline Standard & Title & General information & $\begin{array}{l}\text { Technical } \\
\text { committee }\end{array}$ & $\begin{array}{c}\text { Status / } \\
\text { Publication } \\
\text { date }\end{array}$ \\
\hline \multicolumn{5}{|c|}{ International Organization for Standardization (ISO) } \\
\hline $\begin{array}{l}\text { ISO/TS } \\
\text { 20477:2017 }\end{array}$ & $\begin{array}{l}\text { Nanotechnologies - } \\
\text { Standard terms and their } \\
\text { definition for cellulose } \\
\text { nanomaterial }\end{array}$ & $\begin{array}{l}\text {-Terms and definitions for different types of cellulose } \\
\text { nanomaterials (CNM) including secondary components found } \\
\text { in CNM due to their manufacturing processes. } \\
\text {-Terms are applicable to all types of CNM regardless of } \\
\text { production methods and their origin (plants, animals, algae or } \\
\text { bacteria). }\end{array}$ & $\begin{array}{l}\text { ISO/TC } 229 \\
\text { Nanotechnologies }\end{array}$ & $\begin{array}{l}\text { Published } \\
2017-10\end{array}$ \\
\hline $\begin{array}{l}\text { ISO/TS } \\
16195: 2018\end{array}$ & $\begin{array}{l}\text { Nanotechnologies - } \\
\text { Specification for } \\
\text { developing } \\
\text { representative test } \\
\text { materials consisting of } \\
\text { nano-objects in dry } \\
\text { powder form }\end{array}$ & $\begin{array}{l}\text { - Development of representative test materials consisting of } \\
\text { nano-objects in dry powder form, to enable test method } \\
\text { development and improve comparability of data for } \\
\text { nanotechnology applications. It includes the physico- } \\
\text { chemical properties required to be measured and reported } \\
\text { with the representative test material (e.g. size and shape, } \\
\text { specific surface area, crystal structure, and bulk chemical } \\
\text { composition). }\end{array}$ & $\begin{array}{l}\text { ISO/TC } 229 \\
\text { Nanotechnologies }\end{array}$ & $\begin{array}{l}\text { Published } \\
2018-12\end{array}$ \\
\hline $\begin{array}{l}\text { ISO/TR } \\
\text { 19716:2016 }\end{array}$ & $\begin{array}{l}\text { Nanotechnologies - } \\
\text { Characterization of } \\
\text { cellulose nanocrystals }\end{array}$ & $\begin{array}{l}\text {-Review of the commonly used methods for the } \\
\text { characterization of NCC, including sample preparation, } \\
\text { measurement methods and data analysis. } \\
\text {-Selection of the measurements for characterization of NCC } \\
\text { (composition, morphology and surface characteristics) for } \\
\text { commercial production and applications are covered. }\end{array}$ & $\begin{array}{l}\text { ISO/TC } 229 \\
\text { Nanotechnologies }\end{array}$ & $\begin{array}{l}\text { Published } \\
2016-05\end{array}$ \\
\hline $\begin{array}{l}\text { ISO/TR } \\
12885: 2018\end{array}$ & $\begin{array}{l}\text { Nanotechnologies - } \\
\text { Health and safety } \\
\text { practices in occupational } \\
\text { settings relevant to } \\
\text { nanotechnologies }\end{array}$ & $\begin{array}{l}\text {-Description of health and safety practices in occupational } \\
\text { settings relevant to nanotechnologies }\end{array}$ & $\begin{array}{l}\text { ISO/TC } 229 \\
\text { Nanotechnologies }\end{array}$ & $\begin{array}{l}\text { Published } \\
2018-12\end{array}$ \\
\hline $\begin{array}{l}\text { ISO } \\
21400: 2018\end{array}$ & $\begin{array}{l}\text { Pulp - Determination of } \\
\text { cellulose nanocrystal } \\
\text { sulfur and sulfate half- } \\
\text { ester content }\end{array}$ & $\begin{array}{l}\text {-Determination of the total elemental sulfur and the sulfate } \\
\text { half-ester content of NCC by inductively coupled plasma- } \\
\text { optical emission spectroscopy and conductometric titration, } \\
\text { respectively, including sample preparation, measurement } \\
\text { methods and data analysis. }\end{array}$ & $\begin{array}{l}\text { ISO/TC } 6 \text { Paper, } \\
\text { board and pulps }\end{array}$ & $\begin{array}{l}\text { Published } \\
2018-12\end{array}$ \\
\hline ISO/TS 21346 & $\begin{array}{l}\text { Nanotechnologies - } \\
\text { Characterization of } \\
\text { individualized cellulose } \\
\text { nanofibril samples }\end{array}$ & -This standard is under development & $\begin{array}{l}\text { ISO/TC } 229 \\
\text { Nanotechnologies }\end{array}$ & $\begin{array}{l}\text { Under } \\
\text { development }\end{array}$ \\
\hline
\end{tabular}




\begin{tabular}{|c|c|c|c|c|}
\hline $\begin{array}{l}\text { ISO/DTS } \\
23151\end{array}$ & $\begin{array}{l}\text { Nanotechnologies - } \\
\text { Particle size distribution } \\
\text { for cellulose nanocrystals }\end{array}$ & -This standard is under development & $\begin{array}{l}\text { ISO/TC } 229 \\
\text { Nanotechnologies }\end{array}$ & $\begin{array}{l}\text { Under } \\
\text { development }\end{array}$ \\
\hline ISO/AWI 4989 & $\begin{array}{l}\text { Cellulose Nanomaterial } \\
\text { (CNM) - Sample } \\
\text { Preparation of Pressed } \\
\text { CNM Powder for } \\
\text { Determination of Optical } \\
\text { Properties - ISO } \\
\text { Brightness and L*a*b* } \\
\text { Colour }\end{array}$ & -This standard is under development & $\begin{array}{l}\text { ISO/TC } 6 \text { Paper, } \\
\text { board and pulps }\end{array}$ & $\begin{array}{l}\text { Under } \\
\text { development }\end{array}$ \\
\hline $\begin{array}{l}\text { ISO/FDIS 638- } \\
1\end{array}$ & $\begin{array}{l}\text { Paper, board, pulps and } \\
\text { cellulosic nanomaterials }\end{array}$ & $\begin{array}{l}\text {-Part 1: Materials in solid form } \\
\text {-This standard is under development }\end{array}$ & $\begin{array}{l}\text { ISO/TC } 6 \text { Paper, } \\
\text { board and pulps }\end{array}$ & $\begin{array}{l}\text { Under } \\
\text { development }\end{array}$ \\
\hline $\begin{array}{l}\text { ISO/FDIS 638- } \\
2\end{array}$ & $\begin{array}{l}\text { matter content by oven- } \\
\text { drying method }\end{array}$ & $\begin{array}{l}\text {-Part 2: Suspensions of cellulosic nanomaterials } \\
\text {-This standard is under development }\end{array}$ & $\begin{array}{l}\text { ISO/TC } 6 \text { Paper, } \\
\text { board and pulps }\end{array}$ & $\begin{array}{l}\text { Under } \\
\text { development }\end{array}$ \\
\hline \multicolumn{5}{|c|}{ Canadian Standards Association (CSA) group } \\
\hline $\begin{array}{l}\text { CAN/CSA } \\
\text { Z12885-12 } \\
(\text { R2017) }\end{array}$ & $\begin{array}{l}\text { Nanotechnologies- } \\
\text { Exposure Control } \\
\text { Program for Engineered } \\
\text { Nanomaterials in } \\
\text { Occupational Settings }\end{array}$ & $\begin{array}{l}\text {-It is based on ISO/TR } 12885 \text { and contains revisions and } \\
\text { additional guidance to reflect Canadian practices and safety } \\
\text { considerations. }\end{array}$ & - & $\begin{array}{l}\text { Published } \\
\text { 2012-01 }\end{array}$ \\
\hline $\begin{array}{l}\text { CAN/CSA } \\
\text { Z5100-17 }\end{array}$ & $\begin{array}{l}\text { Cellulosic nanomaterials } \\
\text { - Test methods for } \\
\text { characterization }\end{array}$ & $\begin{array}{l}\text {-Test methods for characterization of CNM, specifically those } \\
\text { designated as NCC, NFC and MFC. }\end{array}$ & - & $\begin{array}{l}\text { Published } \\
\text { 2017-01 } \\
\text { (first edition } \\
\text { in 2014) }\end{array}$ \\
\hline $\begin{array}{l}\text { CAN/CSA- } \\
\text { Z5200-17 }\end{array}$ & $\begin{array}{l}\text { Cellulose nanomaterials - } \\
\text { Blank detail specification }\end{array}$ & $\begin{array}{l}\text { - Guidance and a blank detail specification for determining } \\
\text { and listing essential properties and characteristics with } \\
\text { reference to corresponding test methods in CSA Z5100 and } \\
\text { other standards. }\end{array}$ & - & $\begin{array}{l}\text { Published } \\
2017-01\end{array}$ \\
\hline $\begin{array}{l}\text { CAN/CSA } \\
\text { Z5300-19 }\end{array}$ & $\begin{array}{l}\text { Cellulose filaments (CF) - } \\
\text { Preparing handsheets for } \\
\text { physical tests }\end{array}$ & $\begin{array}{l}\text { - Methods for the preparation of low-basis weight handsheets } \\
\text { of CF, NFC and MFC to be used for physical tests. }\end{array}$ & - & $\begin{array}{l}\text { Published } \\
2019-12\end{array}$ \\
\hline
\end{tabular}


In 2011, the international experts who attended to TAPPI's International Standards Workshop held in Washington, D.C. (EEUU) agreed to start coordinating the development of international standards for NC, which includes the standardization in four categories: (a) terminology and nomenclature; (b) measurement and characterization; (c) environment, health, and safety (EHS); and (d) material specifications. These categories align with the four working Groups established within ISO TC 229. As a result, a Roadmap document was written at this time by a group of experts following the sessions conducted at the workshop, and the main goals of this roadmap were summarized as follows: highlight the key strategic and tactical ways to develop suitable standards for NC; generate awareness in standards development for NC materials within different sectors (i.e. industry, government...); engagement all professional fields to participate in NC standards development; and address possible international trade barriers, regulation development, and policy issues (TAPPI 2011). Key participants and contributors to this roadmap have formed the "International Nanocellulose Standards Coordination Committee (INSCC)". This roadmap is a living document and it is updated as the knowledge of NC is advanced in the different sectors, which include academia, industry, and the government policies.

Recently, Pyrgiotakis et al. (2018) have pointed out that one of the main reason of discrepancies in the results between researches is associated with the lack of standardized methods to produce industry relevant reference NC. Therefore, the development of standardized NFC and NCC with reproducible and consistent properties is also a key factor to compare results from different research studies, to develop standard methodology to determine physical, chemical, mechanical, and toxicological properties and to promote the industrial scale production and the commercialization of the NC products.

\section{CONCLUSIONS}

One of the main factors hindering the commercial deployment of nanomaterials is the absence of fast and robust characterization methods to perform an efficient process and quality control along the production chain. This problem is particularly significant for the emerging NC industry. Despite the excellent properties of NC, the market is still far from reaching its full potential. Among the main causes for this is the lack of process-adapted measuring tools capable of characterizing NC at acceptable speed and reliability to meet the industrial demands in a cost-effective way.

Moreover, due to the wide range of applications, gaining deeper knowledge about $\mathrm{NC}$ with faster and more efficient techniques and methods to apply in research as well as at an industrial scale, for instance, in controlling processes, is crucial. With the vastly different particle morphologies and surface chemistries, NCC and NFC will interact and respond to a given industrial environment or application in very different ways, dictating their colloidal stability, self-assembly, and agglomeration behavior, as well as NC-NC and NC-polymer interfacial bond strength that determines their dispersibility, and reinforcement potential. All these properties affect the quality of the NC and all ensuing uses of these materials. This also follows through to their characterization.

Characterization methods of NC need to be fast, reliable, precise, validated, and used in more than one laboratory. For some techniques, characterization approaches for NCC and NFC are similar, whereas in others they can be very different. NCC may be easier to characterize, although their dispersion/aggregation characterization is challenging, whereas NFC particles do not have a well-defined size and shape, and their rheological 
properties determine their behavior. Viscosity or the resistance to flow is quite sensitive to changes in morphology and composition in a NFC-based product. Therefore, rheological analysis of the shear dependent viscoelastic response is adequate for evaluating the contribution of NFC properties such as concentration, particle size, morphology, and surface functionality to control and manage their processability and to evaluate the quality of dispersion. Moreover, it is of the utmost importance to develop reference standards for $\mathrm{NC}$ products and for their characterization based on the best available technologies.

\section{ACKNOWLEDGMENTS}

The authors are grateful for the financial support by the Economy and Competitiveness Ministry of Spain (project CTQ2017-85654-C2-2-R) and the Community of Madrid (project S2018/EMT-4459; RETO-PROSOST2-CM).

\section{REFERENCES CITED}

Abdul Khalil, H. P. S., Davoudpour, Y., Islam, M. N., Mustapha, A., Sudesh, K., Dungani, R., and Jawaid, M. (2014). "Production and modification of nanofibrillated cellulose using various mechanical processes: A review," Carbohydrate Polymers 99, 649-665. DOI: 10.1016/j.carbpol.2013.08.069

Alexandrescu, L., Syverud, K., Gatti, A., and Chinga-Carrasco, G. (2013). “Cytotoxicity tests of cellulose nanofibril-based structures," Cellulose 20(4), 1765-1775. DOI: 10.1007/s10570-013-9948-9

Ang, S., Narayanan, J. R., Kargupta, W., Haritos, V., and Batchelor, W. (2020). "Cellulose nanofiber diameter distributions from microscopy image analysis: Effect of measurement statistics and operator," Cellulose 27, 4189-4208. DOI: 10.1007/s10570-020-03058-0

Balea, A., Blanco, A., and Negro, C. (2019). "Nanocelluloses: Natural-based materials for fiber-reinforced cement composites. A critical review," Polymers 11(3), 518. DOI: $10.3390 /$ polym 11030518

Balea, A., Merayo, N., Fuente, E., Negro, C., and Blanco, A. (2016). "Assessing the influence of refining, bleaching and TEMPO-mediated oxidation on the production of more sustainable cellulose nanofibers and their application as paper additives," Industrial Crops and Products 97, 374-387. DOI: 10.1016/j.indcrop.2016.12.050

Balea, A., Monte, M. C., Merayo, N., Campano, C., Negro, C., and Blanco, A. (2020). "Industrial application of nanocelluloses in papermaking: A review of challenges, technical solutions, and market perspectives," Molecules 25(3), 526. DOI: 10.3390/molecules25030526

Barhoum, A., Li, H., Chen, M., Cheng, L., Yang, W., and Dufresne, A. (2019). "Emerging applications of cellulose nanofibers," in: Handbook of Nanofibers, A. Barhoum, M. Bechelany, and A. S. H. Makhlouf (eds.), Springer International Publishing. Cham, pp. 1131-1156. DOI: 10.1007/978-3-319-53655-2_53

Beck, S., and Bouchard, J. (2014). "Auto-catalyzed acidic desulfation of cellulose nanocrystals," Nordic Pulp \& Paper Research Journal 29(1), 6-14. DOI: 10.3183/npprj-2014-29-01-p006-014 
Beck, S., Bouchard, J., and Berry, R. (2012). "Dispersibility in water of dried nanocrystalline cellulose," Biomacromolecules 13(5), 1486-1494. DOI: $10.1021 / \mathrm{bm} 300191 \mathrm{k}$

Bhattacharjee, S. (2016). "DLS and zeta potential-What they are and what they are not?," Journal of Controlled Release 235, 337-351. DOI: 10.1016/j.jconrel.2016.06.017

Blanco, A., Monte, M. C., Campano, C., Balea, A., Merayo, N., and Negro, C. (2018). "Nanocellulose for industrial use: Cellulose nanofibers (CNF), cellulose nanocrystals (CNC), and bacterial cellulose (BC)," in: Handbook of Nanomaterials for Industrial Applications, Elsevier, pp. 74-126. DOI: 10.1016/B978-0-12-813351-4.00005-5

Blanco, A., Negro, C., Monte, M. C., Otero, D., and Tijero, J. (2000). "New system to predict deposits due to DCM destabilization in paper mills," Pulp \& paper Canada 101(9), 40-43.

Burger, S., Eberl, C., Siegel, A., Ludwig, A., and Kraft, O. (2011a). "A novel highthroughput fatigue testing method for metallic thin films," Science and Technology of Advanced Materials 12, 1-7. DOI: 10.1088/1468-6996/12/5/054202

Burger, S., Rupp, B., Ludwig, A., Kraft, O., and Eberl, C. (2011b). "Fatigue testing of thin films," in: Key Engineering Materials, Trans Tech Publ., pp. 552-555. DOI: 10.4028/www.scientific.net/KEM.465.552

Butchosa, N., and Zhou, Q. (2014). "Water redispersible cellulose nanofibrils adsorbed with carboxymethyl cellulose," Cellulose 21(6), 4349-4358. DOI: 10.1007/s10570014-0452-7

Camarero-Espinosa, S., Endes, C., Mueller, S., Petri-Fink, A., Rothen-Rutishauser, B., Weder, C., Clift, M. J. D., and Foster, E. J. (2016). "Elucidating the potential biological impact of cellulose nanocrystals," Fibers 4(3), 21. DOI: 10.3390/fib4030021

Campano, C., Balea, A., Blanco, Á., and Negro, C. (2020a). "A reproducible method to characterize the bulk morphology of cellulose nanocrystals and nanofibers by transmission electron microscopy," Cellulose 27(9), 4871-4887. DOI: 10.1007/s10570-020-03138-1

Campano, C., Lopez-Exposito, P., Gonzalez-Aguilera, L., Blanco, Á., and Negro, C. (2020b). "In-depth characterization of the aggregation state of cellulose nanocrystals through analysis of transmission electron microscopy images," Carbohydrate Polymers, 117271. Available online 23 October 2020, 117271. DOI: 10.1016/j.carbpol.2020.117271.

Campano, C., Merayo, N., Balea, A., Tarrés, Q., Delgado-Aguilar, M., Mutjé, P., Negro, C., and Blanco, Á. (2018a). "Mechanical and chemical dispersion of nanocelluloses to improve their reinforcing effect on recycled paper," Cellulose 25(1), 269-280. DOI: $10.1007 / \mathrm{s} 10570-017-1552-\mathrm{y}$

Campano, C., Merayo, N., Negro, C., and Blanco, A. (2018b). "Low-fibrillated bacterial cellulose nanofibers as a sustainable additive to enhance recycled paper quality," International Journal of Biological Macromolecules 114, 1077-1083. DOI: 10.1016/j.ijbiomac.2018.03.170

Ciampa, F., Mahmoodi, P., Pinto, F., and Meo, M. (2018). "Recent advances in active infrared thermography for non-destructive testing of aerospace components," Sensors 18(2), 37. DOI: 10.3390/s 18020609

Colson, J., Bauer, W., Mayr, M., Fischer, W., and Gindl-Altmutter, W. (2016). "Morphology and rheology of cellulose nanofibrils derived from mixtures of pulp 
fibres and papermaking fines," Cellulose 23(4), 2439-2448. DOI: 10.1007/s10570016-0987-X

Chinga-Carrasco, G., Yu, Y., and Diserud, O. (2011). "Quantitative electron microscopy of cellulose nanofibril structures from Eucalyptus and Pinus radiata kraft pulp fibers," Microscopy and Microanalysis 17(4), 563. DOI: 10.1017/S1431927611000444

Chinga-Carrasco, G. (2013). "Optical methods for the quantification of the fibrillation degree of bleached MFC materials," Micron 48, 42-48. DOI:

10.1016/j.micron.2013.02.005

Chinga-Carrasco, G., Averianova, N., Kondalenko, O., Garaeva, M., Petrov, V., Leinsvang, B., and Karlsen, T. (2014). "The effect of residual fibres on the microtopography of cellulose nanopaper," Micron 56, 80-84. DOI: doi.org/10.1016/j.micron.2013.09.002

Chu, Y., Sun, Y., Wu, W., and Xiao, H. (2020). "Dispersion properties of nanocellulose: A review," Carbohydrate Polymers 250, 1-17, article no. 116892. DOI: 10.1016/j.carbpol.2020.116892

Desmaisons, J., Boutonnet, E., Rueff, M., Dufresne, A., and Bras, J. (2017). “A new quality index for benchmarking of different cellulose nanofibrils," Carbohydrate Polymers 174, 318-329. DOI: 10.1016/j.carbpol.2017.06.032

Dufrêne, Y. F. (2002). "Atomic force microscopy, a powerful tool in microbiology," Journal of Bacteriology 184(19), 5205-5213. DOI: 10.1128/JB.184.19.52055213.2002

Dufresne, A. (2019). "Nanocellulose processing properties and potential applications," Current Forestry Reports 5(2), 76-89. DOI: 10.1007/s40725-019-00088-1

Endes, C., Camarero-Espinosa, S., Mueller, S., Foster, E., Petri-Fink, A., RothenRutishauser, B., Weder, C., and Clift, M. (2016). "A critical review of the current knowledge regarding the biological impact of nanocellulose," Journal of Nanobiotechnology 14(1), 78. DOI: 10.1186/s12951-016-0230-9

Espinosa, E., Tarres, Q., Delgado-Aguilar, M., Gonzalez, I., Mutje, P., and Rodriguez, A. (2016). "Suitability of wheat straw semichemical pulp for the fabrication of lignocellulosic nanofibres and their application to papermaking slurries," Cellulose 23(1), 837-852. DOI: $10.1007 / \mathrm{s} 10570-015-0807-8$

European Comission (2018). "Open innovation test beds guidelines for internal management and access conditions," European Comission. Work Programme H2020 2018-2020.

Eyholzer, C., Bordeanu, N., Lopez-Suevos, F., Rentsch, D., Zimmermann, T., and Oksman, K. (2010). "Preparation and characterization of water-redispersible nanofibrillated cellulose in powder form," Cellulose 17(1), 19-30. DOI: 10.1007/s10570-009-9372-3

Fedotov, P. S., Vanifatova, N. G., Shkinev, V. M., and Spivakov, B. Y. (2011). "Fractionation and characterization of nano-and microparticles in liquid media," Analytical and Bioanalytical Chemistry 400(6), 1787-1804. DOI: 10.1007/s00216011-4704-1

Foster, E. J., Moon, R. J., Agarwal, U. P., Bortner, M. J., Bras, J., Camarero-Espinosa, S., Chan, K. J., Clift, M. J., Cranston, E. D., and Eichhorn, S. J. (2018). "Current characterization methods for cellulose nanomaterials," Chemical Society Reviews 47(8), 2609-2679. DOI: 10.1039/C6CS00895J 
Fraschini, C., Chauve, G., Le Berre, J.-F., Ellis, S., Méthot, M., O’Connor, B., and Bouchard, J. (2014). "Critical discussion of light scattering and microscopy techniques for CNC particle sizing," Nordic Pulp \& Paper Research Journal 29(1), 31-40. DOI: 10.3183/npprj-2014-29-01-p031-040

Fukuzumi, H., Saito, T., Okita, Y., and Isogai, A., (2010). "Thermal stabilization of TEMPO-oxidized cellulose," Polymer Degradation and Stability 95(9), 1502-1508. DOI: 10.1016/j.polymdegradstab.2010.06.015

FutureMarkets. (2019). "Nanocellulose Investment and Pricing Guide 2018," Inc.: Dublin, Ireland.

Habibi, Y. (2014). "Key advances in the chemical modification of nanocelluloses," Chemical Society Reviews 43(5), 1519-1542. DOI: 10.1039/C3CS60204D

Habibi, Y., Lucia, L. A., and Rojas, O. J. (2010). "Cellulose nanocrystals: Chemistry, self-assembly, and applications," Chemical Reviews 110(6), 3479-3500. DOI: $10.1021 / \mathrm{cr} 900339 \mathrm{w}$

Heggset, E. B., Chinga-Carrasco, G., and Syverud, K. (2017). "Temperature stability of nanocellulose dispersions," Carbohydrate Polymers 157, 114-121. DOI: 10.1016/j.carbpol.2016.09.077

Hubbe, M. A., Tayeb, P., Joyce, M., Tyagi, P., Kehoe, M., Dimic-Misic, K., and Pal, L. (2017). "Rheology of nanocellulose-rich aqueous suspensions: A review," BioResources 12(4), 9556-9661. DOI: 10.15376/biores.12.1.2143-2233

Inglesby, M., and Zeronian, S. (2002). "Direct dyes as molecular sensors to characterize cellulose substrates," Cellulose 9(1), 19-29. DOI: 10.1023/A:1015840111614

ISO Standard (2019). "Good standardization practices," International Organization for Standardization.

Isogai, A. (2020). "Emerging nanocellulose technologies: Recent developments," Advanced Materials, article no. 2000630. DOI: 10.1002/adma.202000630

Jiang, F., and Hsieh, Y.-L. (2013). "Chemically and mechanically isolated nanocellulose and their self-assembled structures," Carbohydrate Polymers 95(1), 32-40. DOI: 10.1016/j.carbpol.2013.02.022

Jowkarderis, L., and van de Ven, T. G. (2014). "Intrinsic viscosity of aqueous suspensions of cellulose nanofibrils," Cellulose 21(4), 2511-2517. DOI: 10.1007/s 10570-014-0292-5

Kangas, H., Lahtinen, P., Sneck, A., Saariaho, A.-M., Laitinen, O., and Hellen, E. (2014). "Characterization of fibrillated celluloses. A short review and evaluation of characteristics with a combination of methods," Nordic Pulp \& Paper Research Journal 29(1), 129-143. DOI: 10.3183/npprj-2014-29-01-p129-143

Kargarzadeh, H., Mariano, M., Gopakumar, D., Ahmad, I., Thomas, S., Dufresne, A., Huang, J., and Lin, N. (2018). "Advances in cellulose nanomaterials," Cellulose 25(4), 2151-2189. DOI: 10.1007/s10570-018-1723-5

Kargarzadeh, H., Mariano, M., Huang, J., Lin, N., Ahmad, I., Dufresne, A., and Thomas, S. (2017). "Recent developments on nanocellulose reinforced polymer nanocomposites: A review," Polymer 132, 368-393. DOI:

10.1016/j.polymer.2017.09.043

Kaushik, M., Chen, W. C., van de Ven, T. G., and Moores, A. (2014). “An improved methodology for imaging cellulose nanocrystals by transmission electron microscopy," Nordic Pulp \& Paper Research Journal 29(1), 77-84. DOI: 10.3183/npprj-2014-29-01-p077-084 
Kaushik, M., Fraschini, C., Chauve, G., Putaux, J.-L., and Moores, A. (2015). "Transmission electron microscopy for the characterization of cellulose nanocrystals," in: The Transmission Electron Microscope - Theory and Applications, M. Khan (ed.), September 2015. DOI: 10.5772/60985

Klemm, D., Cranston, E. D., Fischer, D., Gama, M., Kedzior, S. A., Kralisch, D., Kramer, F., Kondo, T., Lindström, T., and Nietzsche, S. (2018). "Nanocellulose as a natural source for groundbreaking applications in materials science: Today's state," Materials Today 21(7), 720-748. DOI: 10.1016/j.mattod.2018.02.001

Kraft, O., and Volkert, C. A. (2001). "Mechanical testing of thin films and small structures," Advanced Engineering Materials 3(3), 99-110. DOI: 10.1002/15272648(200103)3:3<99::AID-ADEM99>3.0.CO;2-2

Lengowski, E. C., Magalhães, W. L. E., Nisgoski, S., de Muniz, G. I. B., Satyanarayana, K. G., and Lazzarotto, M. (2016). "New and improved method of investigation using thermal tools for characterization of cellulose from eucalypts pulp," Thermochimica Acta 638, 44-51. DOI: 10.1016/j.tca.2016.06.010

Li, M.-C., Wu, Q., Song, K., Lee, S., Qing, Y., and Wu, Y. (2015). "Cellulose nanoparticles: Structure-morphology-rheology relationships,” ACS Sustainable Chemistry \& Engineering 3(5), 821-832. DOI: 10.1021/acssuschemeng.5b00144

Li, X., and Bhushan, B. (2002). "A review of nanoindentation continuous stiffness measurement technique and its applications," Materials Characterization 48(1), 11 36. DOI: 10.1016/S1044-5803(02)00192-4

Lichtenstein, K., and Lavoine, N. (2017). "Toward a deeper understanding of the thermal degradation mechanism of nanocellulose," Polymer Degradation and Stability 146, 53-60. DOI: 10.1016/j.polymdegradstab.2017.09.018

Lie, E., Ålander, E., and Lindström, T. (2017). "Possible toxicological effects of nanocellulose: An updated literature study," No. 2, Innventia. Stockholm.

Lin, N., and Dufresne, A. (2014). "Nanocellulose in biomedicine: Current status and future prospect," European Polymer Journal 59, 302-325. DOI:

10.1016/j.eurpolymj.2014.07.025

Lindström, T., Naderi, A., and Wiberg, A. (2015). "Large scale applications of nanocellulosic materials - A comprehensive review," Journal of Korea TAPPI 47(6), 5-21. DOI: 10.7584/ktappi.2015.47.6.005

Mao, Y., Liu, K., Zhan, C., Geng, L., Chu, B., and Hsiao, B. S. (2017). "Characterization of nanocellulose using small-angle neutron, X-ray, and dynamic light scattering techniques," The Journal of Physical Chemistry B 121(6), 1340-1351. DOI: 10.1021/acs.jpcb.6b11425

MarketandMarkets ${ }^{\mathrm{TM}}$. (2018). "Nanocellulose Market worth $\$ 661.7$ million by 2023. Markets and Markets, PRNewswire, Chicago, October,16, 2018."

Marway, H. (2017). Nanocellulose Properties Measured by Atomic Force Microscopy, Master Thesis McMaster University.

Mattos, B. D., Tardy, B. L., and Rojas, O. J. (2019). "Accounting for substrate interactions in the measurement of the dimensions of cellulose nanofibrils," Biomacromolecules 20(7), 2657-2665. DOI: 10.1021/acs.biomac.9b00432

Miller, J. (2019a). Biobased Markets in Nanocellulose: Packaging Applications and Markets, Fastmarkets RISI, Bedford, MA, USA.

Miller, J. (2019b). "Nanocellulose: Market perspectives," Tappi Journal 18(5), 313-316.

Missoum, K., Belgacem, M. N., and Bras, J. (2013). "Nanofibrillated cellulose surface modification: A review," Materials 6(5), 1745-1766. DOI: 10.3390/ma6051745 
Missoum, K., Bras, J., and Belgacem, M. N. (2012). "Water redispersible dried nanofibrillated cellulose by adding sodium chloride," Biomacromolecules 13(12), 4118-4125. DOI: $10.1021 / \mathrm{bm} 301378$ n

Mondal, S. (2017). "Preparation, properties and applications of nanocellulosic materials," Carbohydrate Polymers 163, 301-316. DOI: 10.1016/j.carbpol.2016.12.050

Moser, C. (2018). Manufacturing and Characterization of Cellulose Nanofibers, KTH Royal Institute of Technology.

Moser, C., Lindström, M. E., and Henriksson, G. (2015). "Toward industrially feasible methods for following the process of manufacturing cellulose nanofibers," BioResources 10(2), 2360-2375. DOI: 10.15376/biores.10.2.2360-2375

Nair, S. S., Zhu, J. Y., Deng, Y., and Ragauskas, A. J. (2014). "High performance green barriers based on nanocellulose," Sustainable Chemical Processes 2(1), 1-7. DOI: 10.1186/s40508-014-0023-0

Nanocellulose Market, P.a.P.R. (2019). Published by Future Markets, Inc., August 2019

Nixon-Luke, R., and Bryant, G. (2019). "A depolarized dynamic light scattering method to calculate translational and rotational diffusion coefficients of nanorods," Particle \& Particle Systems Characterization 36(2), 7. DOI: 10.1002/ppsc.201800388

Osong, S. H., Norgren, S., and Engstrand, P. (2016). "Processing of wood-based microfibrillated cellulose, and applications relating to papermaking: A review," Cellulose 23(1), 93-123. DOI: 10.1007/s10570-015-0798-5

Österberg, M., Vartiainen, J., Lucenius, J., Hippi, U., Seppälä, J., Serimaa, R., and Laine, J. (2013). "A fast method to produce strong NFC films as a platform for barrier and functional materials," ACS Applied Materials \& Interfaces 5(11), 4640-4647. DOI: 10.1021/am401046x

Panaitescu, D. M., Vizireanu, S., Nicolae, C. A., Frone, A. N., Casarica, A., Carpen, L. G., and Dinescu, G. (2018). "Treatment of nanocellulose by submerged liquid plasma for surface functionalization," Nanomaterials 8(7), 467-484. DOI: 10.3390/nano8070467

Patiño-Masó, J., Serra-Parareda, F., Tarrés, Q., Mutjé, P., Espinach, F. X., and DelgadoAguilar, M. (2019). "TEMPO-oxidized cellulose nanofibers: A potential bio-based superabsorbent for diaper production," Nanomaterials 9(9), 1271. DOI: 10.3390/nano9091271

Peng, Y. C., Gardner, D. J., Han, Y., Kiziltas, A., Cai, Z. Y., and Tshabalala, M. A. (2013). "Influence of drying method on the material properties of nanocellulose. I: thermostability and crystallinity," Cellulose 20(5), 2379-2392. DOI: 10.1007/s10570013-0019-z

Peresin, M. S., Kammiovirta, K., Heikkinen, H., Johansson, L. S., Vartiainen, J., Setälä, H., Österberg, M., and Tammelin, T. (2017). "Understanding the mechanisms of oxygen diffusion through surface functionalized nanocellulose films," Carbohydrate Polymers 174, 309-317. DOI: 10.1016/j.carbpol.2017.06.066

Pouwels, A. D., Eijkel, G. B., and Boon J. J. (1989). "Curie-point pyrolysis-capillary gas chromatography - High-resolution mass spectrometry of microcrystalline cellulose," Journal of Analytical and Applied Pyrolysis 14(4), 237-280. DOI: 10.1016/01652370(89)80003-8

Pyrgiotakis, G., Luu, W., Zhang, Z., Vaze, N., DeLoid, G., Rubio, L., Graham, W. A. C., Bell, D. C., Bousfield, D., and Demokritou, P. (2018). "Development of high throughput, high precision synthesis platforms and characterization methodologies for 
toxicological studies of nanocellulose," Cellulose 25(4), 2303-2319. DOI: 10.1007/s10570-018-1718-2

Reid, M. S., Villalobos, M., and Cranston, E. D. (2017a). "Benchmarking cellulose nanocrystals: From the laboratory to industrial production," Langmuir 33(7), 15831598. DOI: 10.1021/acs.langmuir.6b03765

Reid, M. S., Villalobos, M., and Cranston, E. D. (2016). “Cellulose nanocrystal interactions probed by thin film swelling to predict dispersibility," Nanoscale 8(24), 12247-12257. DOI: 10.1039/C6NR01737A

Reid, M. S., Villalobos, M., and Cranston, E. D. (2017b). "The role of hydrogen bonding in non-ionic polymer adsorption to cellulose nanocrystals and silica colloids," Current Opinion in Colloid \& Interface Science 29, 76-82. DOI: 10.1016/j.cocis.2017.03.005

Roadmap for Materials Characterization, European Materials Characterization Council (EMCC), http://www.characterization.eu/index.php/publications-output

Roman, M. (2015). "Toxicity of cellulose nanocrystals: A review," Industrial Biotechnology 11(1), 25-33. DOI: 10.1089/ind.2014.0024

Sahlin, K., Forsgren, L., Moberg, T., Bernin, D., Rigdahl, M., and Westman, G. (2018). "Surface treatment of cellulose nanocrystals (CNC): Effects on dispersion rheology," Cellulose 25(1), 331-345. DOI: 10.1007/s10570-017-1582-5

Salas, C., Nypelö, T., Rodriguez-Abreu, C., Carrillo, C., and Rojas, O. J. (2014). "Nanocellulose properties and applications in colloids and interfaces," Current Opinion in Colloid \& Interface Science 19(5), 383-396. DOI: 10.1016/j.cocis.2014.10.003

Sanchez-Salvador, J. L., Monte, M. C., Batchelor, W., Garnier, G., Negro, C., and Blanco, A. (2020). "Characterizing highly fibrillated nanocellulose by modifying the gel point methodology," Carbohydrate Polymers 227, 115340. DOI: 10.1016/j.carbpol.2019.115340

Seabra, A. B., Bernardes, J. S., Fávaro, W. J., Paula, A. J., and Durán, N. (2018). "Cellulose nanocrystals as carriers in medicine and their toxicities: A review," Carbohydrate Polymers 181, 514-527. DOI: 10.1016/j.carbpol.2017.12.014

Shatkin, J. A., and Kim, B. (2015). "Cellulose nanomaterials: Life cycle risk assessment, and environmental health and safety roadmap," Environmental Science-Nano 2(5), 477-499. DOI: 10.1039/C5EN00059A

Shimizu, M., Saito, T., Nishiyama, Y., Iwamoto, S., Yano, H., Isogai, A., and Endo, T. (2016). "Fast and robust nanocellulose width estimation using turbidimetry," Macromolecular Rapid Communications 37(19), 1581-1586. DOI: 10.1002/marc.201600357

Shinoda, R., Saito, T., Okita, Y., and Isogai, A. (2012). "Relationship between length and degree of polymerization of TEMPO-oxidized cellulose nanofibrils," Biomacromolecules 13(3), 842-849. DOI: 10.1021/bm2017542

Shrestha, S., Diaz, J. A., Ghanbari, S., and Youngblood, J. P. (2017). "Hygroscopic swelling determination of cellulose nanocrystal (CNC) films by polarized light microscopy digital image correlation," Biomacromolecules 18(5), 1482-1490. DOI: 10.1021/acs.biomac.7b00026

Souza, E., Gottschalk, L., and Freitas-Silva, O. (2020). "Overview of nanocellulose in food packaging," Recent Patents on Food, Nutrition \& Agriculture 11(2), 154-167. DOI: $10.2174 / 2212798410666190715153715$ 
Stoudmann, N., Nowack, B., and Som, C. (2019). "Prospective environmental risk assessment of nanocellulose for Europe," Environmental Science: Nano 6(8), 25202531. DOI: 10.1039/C9EN00472F

Takaichi, S., Saito, T., Tanaka, R., and Isogai, A. (2014). "Improvement of nanodispersibility of oven-dried TEMPO-oxidized celluloses in water," Cellulose 21(6), 4093-4103. DOI: 10.1007/s10570-014-0444-7

Tanaka, R., Saito, T., Ishii, D., and Isogai, A. (2014). "Determination of nanocellulose fibril length by shear viscosity measurement," Cellulose 21(3), 1581-1589. DOI: 10.1007/s10570-014-0196-4

TAPPI. (2011). Roadmap for the Development of International Standards for Nanocellulose, Technical Association for the Pulp and Paper Industry, Atlanta, GA, USA.

Tarrés, Q., Boufi, S., Mutjé, P., and Delgado-Aguilar, M. (2017). "Enzymatically hydrolyzed and TEMPO-oxidized cellulose nanofibers for the production of nanopapers: morphological, optical, thermal and mechanical properties," Cellulose 24(9), 3943-3954. DOI: 10.1007/s10570-017-1394-7

Tarrés, Q., Mutjé, P., and Delgado-Aguilar, M. (2019). "Towards the development of highly transparent, flexible and water-resistant bio-based nanopapers: Tailoring physico-mechanical properties," Cellulose 26(11), 6917-6932. DOI: 10.1007/s10570019-02524-8

Tarrés, Q., Oliver-Ortega, H., Alcalà, M., Espinach, F. X., Mutjé, P., and DelgadoAguilar, M. (2020). "Research on the strengthening advantages on using cellulose nanofibers as polyvinyl alcohol reinforcement," Polymers 12(4), 974. DOI: 10.3390/polym 12040974

Tayeb, A. H., Amini, E., Ghasemi, S., and Tajvidi, M. (2018). "Cellulose nanomaterials - binding properties and applications: A review," Molecules 23(10), 2684. DOI: $10.3390 /$ molecules 23102684

Tejado, A., Alam, M. N., Antal, M., Yang, H., and van de Ven, T. G. M. (2012). "Energy requirements for the disintegration of cellulose fibers into cellulose nanofibers," Cellulose 19(3), 831-842. DOI: 10.1007/s10570-012-9694-4

Trache, D., Hussin, M. H., Haafiz, M. M., and Thakur, V. K. (2017). "Recent progress in cellulose nanocrystals: Sources and production," Nanoscale 9(5), 1763-1786.

Trache, D., Tarchoun, A. F., Derradji, M., Hamidon, T. S., Masruchin, N., Brosse, N., and Hussin, M. H. (2020). "Nanocellulose: From fundamentals to advanced applications," Frontiers in Chemistry 8. DOI: 10.3389/fchem.2020.00392

Ureña-Benavides, E. E., and Kitchens, C. L. (2012). "Static light scattering of triaxial nanoparticle suspensions in the Rayleigh-Gans-Debye regime: Application to cellulose nanocrystals," RSC Advances 2(3), 1096-1105. DOI: 10.1039/C1RA00391G

Vadakkekara, G. J., Thomas, S., and Nair, C. R. (2020). "Sodium itaconate grafted nanocellulose for facile elimination of lead ion from water," Cellulose 27(6), 32333248. DOI: 10.1007/s10570-020-02983-4

Velásquez-Cock, J., Gañán, P., Posada, P., Castro, C., Serpa, A., Putaux, J. L., and Zuluaga, R. (2016). "Influence of combined mechanical treatments on the morphology and structure of cellulose nanofibrils: Thermal and mechanical properties of the resulting films," Industrial Crops and Products 85, 1-10. DOI: 10.1016/j.indcrop.2016.02.036 
Vilarinho, F., Sanches Silva, A., Vaz, M. F., and Farinha, J. P. (2018). "Nanocellulose in green food packaging," Critical Reviews in Food Science and Nutrition 58(9), 15261537. DOI: 10.1080/10408398.2016.1270254

Wang, Q., Yao, Q., Liu, J., Sun, J., Zhu, Q., and Chen, H. (2019). “Processing nanocellulose to bulk materials: A review," Cellulose, 1-33. DOI: 10.1007/s10570019-02642-3

Wang, K., Lu, J., Tusiime, R., Yang, Y., Fan, F., Zhang, H., and Ma, B. (2020). "Properties of poly (1-lactic acid) reinforced by l-lactic acid grafted nanocellulose crystal," International Journal of Biological Macromolecules 156, 314-320. DOI: 10.1016/j.ijbiomac.2020.04.025

Xiao, Y., Rong, L., Wang, B., Mao, Z., Xu, H., Zhong, Y., Zhang, L., and Sui, X. (2018). "A light-weight and high-efficacy antibacterial nanocellulose-based sponge via covalent immobilization of gentamicin," Carbohydrate Polymers 200, 595-601. DOI: 10.1016/j.carbpol.2018.07.091

$\mathrm{Xu}, \mathrm{R}$. (2015). "Light scattering: A review of particle characterization applications," Particuology 18, 11-21. DOI: 10.1016/j.partic.2014.05.002

Zhou, Y., Huang, X., Huang, J., Zhang, L., and Zhou, Z. (2018). "Predicting the dielectric properties of nanocellulose-modified presspaper based on the multivariate analysis method," Molecules 23(7), 1507. DOI: 10.3390/molecules23071507

Article submitted: December 23, 2020; Peer review completed: January 16, 2021;

Revised version received and accepted: February 15, 2021; Published: March 17, 2021.

DOI: 10.15376/biores.16.2.Balea 